\title{
Apresentação Bibliográfica
}

Nietzsche e a aurora de uma nova ética. São Paulo: Humanitas \& Fapesp, 2008, 327p.

Em Nietzsche e a aurora de uma nova ética ${ }^{1}$ tencionamos mostrar, especialmente, que na filosofia de Nietzsche há uma interpretação que conduz da dissolução da metafísica à ética do amor fati. Investigamos os seus textos a partir da hipótese de que em sua filosofia, mormente a que se inicia com Assim falava Zaratustra, aparece a construção de uma ética apresentada por nós como ética do amor fati. Os temas que constituem a vertente positiva do seu pensamento - vontade de potência, eterno retorno e além-do-homem - inter-relacionam-se a partir da perspectiva dessa ética que requer, como condicionante de sua compreensão, a superação da metafísica. Assim, situamos a leitura do pensamento de Nietzsche em uma outra dimensão, pois partimos do pressuposto de que o móvel condutor das suas análises está determinado pela afirmação incondicional da vida. É nessa afirmação que julgamos encontrar elementos para sustentar a hipótese da presença de uma ética no conjunto de sua obra afirmativa, ainda que se configure de modo diverso das formulações anteriores.

Ao nos referirmos especialmente a Assim falava Zaratustra, queremos assinalar um período, na condução do pensamento de Nietzsche, em que são introduzidos os conceitos a partir dos quais ele passa a interpretar o mundo. Efetivamente, distinguimos essa fase das anteriores por reconhecer a construção efetiva do seu pensamento, distanciada, ao mesmo tempo, das influências, por exemplo, de Schopenhauer, presente em O nascimento da tragédia, e do positivismo, constante em Humano, demasiado humano. Convém acrescentar que compartimos, em referência à formulação do pensamento de Nietzsche, com a autora de Das forças cósmicas aos valores humanos, ${ }^{2}$ a compreensão de um primeiro período em que a filosofia de Schopenhauer, a música de Wagner e o estudo

1 O livro Nietzsche e a aurora de uma nova ética (São Paulo: Humanitas \& Fapesp, 2008, 327p.) reproduz, com algumas modificações, a tese de doutorado intitulada Da dissolução da metafísica à ética do amor fati: perspectivas da filosofia positiva de Nietzsche, defendida junto ao Programa de Pós-Graduação da Universidade de São Paulo em março de 2003, sob orientação da profa. Dra. Scarlett Marton. Participaram da banca os professores doutores Franklin Leopoldo e Silva (USP), Olgária C. F. Matos (USP), Benedito Nunes (UFPA) e Márcio Seligmann Silva (Unicamp).

2 Cf. Scarlett Marton, Das forças cósmicas aos valores humanos, Belo Horizonte: Editora da UFMG, 2000. 
filológico constituem o pano de fundo de suas reflexões de 1870 a 1876. De 1878 a 1882, é a influência do positivismo que motiva a investigação de Nietzsche. Já a partir de 1883 as suas obras revelam a sua autêntica filosofia, que se estende aos fragmentos de 1888. Se aceitamos a periodização de Marton, no que concerne ao reconhecimento teórico de motivos condutores que se alteram no percurso filosófico de Nietzsche e na ênfase no terceiro período como sendo o lugar de manifestação de seu pensamento genuíno, marcado sobretudo pela introdução dos conceitos de força, vontade de potência, a doutrina do eterno retorno, o além-do-homem, o procedimento genealógico e a noção de valor, dela nos distanciamos quando da identificação do cerne da filosofia iniciada com Assim falava Zaratustra. Enquanto, para a autora, a cosmologia viabiliza a reorganização do seu pensamento, concebemos a interpretação como o elemento central que permite a Nietzsche, simultaneamente, distanciar-se do sistema semântico da tradição e construir um novo registro que principia por uma interpretação dos existentes até elaborar uma interpretação acerca do agir humano.

Ao tomar a história da filosofia em seu conjunto, Nietzsche refuta as formulações éticas que aparecem como reflexões sobre o agir em busca de um elemento último como seu definidor, ao apresentá-las como imposições de perspectivas. Enquanto os filósofos modernos estabelecem máximas universais e de validade incondicional que respaldam a afirmação da subjetividade como fundante e fornecem parâmetros seguros para compreender e explicar a ação, o autor de Assim falava Zaratustra empreende uma genealogia da moral a fim de realizar o resgate histórico interpretativo das configurações erigidas no decurso da história humana enquanto proposição de sentidos. Ao resgatar motivos não conscientes como determinantes do agir, recusa o governo absoluto da razão em termos de moralidade e a universalidade de sua legislação. Se a idéia e a necessidade de um fundamento absoluto perpassam os pensadores, mormente os da modernidade, entendida como de Descartes a Hegel, enquanto condicionante para compreender e sustentar o conhecer, o ser e o agir, a inexistência de fundamento em Nietzsche conduz, em nossa ótica, da investigação da condição humana inserta no mundo ao reconhecimento de que as considerações acerca do conhecer, do ser e do agir são tão-somente perspectivas provisórias, formas circunstanciais de o homem se situar no mundo.

Ora, ao falar em perspectiva, entendemos que o filósofo alemão exclui de imediato a incondicionalidade e propõe a postulação como base, cujo valor deve ser buscado a partir das condições de criação, ou seja, determinar o móvel mesmo do postular, do avaliar, do interpretar. O dever, por conseguinte, não aparece como constitutivo do ser; ao contrário, suas 
formulações são firmadas a partir de avaliações e, portanto, referidas a uma convenção procedente de uma interpretação. Desse ponto de vista, entendemos que as éticas apareceriam efetivamente como construções, isto é, como imposições de perspectivas acerca do agir humano. É nesse âmbito que inserimos a própria exposição de Nietzsche concernente à ética. Somente nesse domínio pode-se vislumbrar o encadeamento conceptual de sua filosofia construtiva enquanto desenrola-se, partindo de uma interpretação dos existentes e do mundo à sua ação no mundo, do experimento de possibilidades interpretativas à aquiescência ao destino enquanto perspectiva ética. O amor fati, por conseguinte, é uma interpretação resultante do reconhecimento de que não há outra forma de estar no mundo exceto interpretando, tanto o agir quanto a sua conceptualização são interpretações que situam o homem no mundo ao introduzir no mundo o valor. É a partir da noção de interpretação que tratamos da questão ética em Nietzsche, ao reconhecer na anuência ao fatum a expressão de uma perspectiva que afirma incondicionalmente a condição humana desde a construção de perspectivas, a partir do introduzir permanente de interpretações que ao superarem as que se apresentam como mais estreitas, contemplam o advento de outras e revelam o humano em sua competência de criador, assentando o agir em um novo horizonte.

O nosso ponto de partida é a compreensão inicial da vontade de potência, enquanto interpretação que se apresenta como âmbito de sentidos em Nietzsche. É a vontade, entendida como multiplicidade de impulsos em luta permanente, que introduz interpretações, mas, por sua vez, a própria introdução da vontade de potência é uma interpretação possível dos existentes, que se coaduna e abrange as demais interpretações que lhes foram conferidas, ao entender que não há outro âmbito que não o da interpretação. É por isso que apresentamos a vontade de potência como interpretar, como intérprete e como significação que se faz. Ao fazê-lo, recusamos inserir Nietzsche junto aos filósofos metafísicos, por entender que o filósofo procede um deslocamento conceitual da explicação para a interpretação. Não se trata mais de uma pergunta acerca do ente em totalidade, como afirma Heidegger sobre a filosofia nietzschiana, mas da criação de seus possíveis sentidos. Tampouco trata-se da redução dessa filosofia a uma técnica de interpretação, como entende Foucault, pois reconhecemos que o autor introduz um aparato conceptual a partir do qual interpreta o mundo. É isso que Nietzsche afirma quando denuncia a crença exacerbada de um filósofo no conceito contra o afirmar de sua constante criação: "os filósofos (...) não devem mais se contentar em aceitar os conceitos que lhes dão, para somente limpá-los e fazê-los reluzir, mas é preciso que comecem a fabricá-los, 
a criá-los..." (34 [195] do outono de 1884/outono de 1885). Entendendo a filosofia como uma espécie de fábrica de conceitos que expressam interpretações, Nietzsche, em nossa ótica, distancia-se da metafísica e inaugura uma outra forma de abordagem do ser como vir-a-ser, desde o sentido e o valor enquanto interpretação. O mundo que tem valor é o mundo da interpretação, porque se está no mundo desde a interpretação. Os conceitos não dizem algo acerca da realidade, essa questão nem sequer se coloca, mas exprimem perspectivas introduzidas manifestas nos conceitos criados. A metafísica, entendida enquanto pergunta pelo existente em sua totalidade, não se coaduna com a afirmação irrestrita das interpretações postas no curso do tempo.

Ao introduzir a vontade de potência como interpretação, Nietzsche efetua uma reviravolta em termos de interpretação dos existentes. Por um lado, dissolve os conceitos de unidade e substância ao pensar os existentes como multiplicidades de impulsos em luta permanente, cujo termo desfaz-se em um contínuo recomeço que confere ao que devém a característica de um passar, mudar, transformar, sem encontrar unidade ou fixidez, mas impondo incessantemente interpretações. Por outro, ele considera sua exposição como uma interpretação possível, uma vez que supõe não haver outra forma de estar no mundo a não ser interpretando, mas sem a contrapartida de uma unidade subjetiva como intérprete. Quem interpreta é a multiplicidade de vontades de potência que vem a ser o interpretar, o intérprete e a significação que se efetivam enquanto exercer-se. Desencadeia-se, então, a partir dessa outra situação, o seu filosofar como proposição de uma interpretação totalizante, conduzida do primado da interpretação à interpretação do além-do-homem como sujeito ético, do eterno retorno como círculo mundano de interpretações e do amor fati enquanto sua perspectiva ética.

Nietzsche reconhece que houve muitas tábuas de valores, mas nenhuma delas expressando o vir-a-ser, e é em uma inscrição dessa ordem que se encontra o sentido do seu além-do-homem, enquanto expressão da continuidade do avaliar para além das interpretações anteriores. É a incorporação do trágico como medida da vida que se manifesta no além-do-homem, enquanto reconhece tanto a ausência de responsabilidade de seu ser assim quanto de uma primeira causa no mundo como condicionantes de uma inocência inerente ao mundo e ao homem. Em sua mudança de compreensão e ação, assentada na proposição do sujeito como multiplicidade, está a possibilidade de inscrição de novas tábuas valorativas, à medida que se percebe como avaliador, criador. No limite, como aquele que ao introduzir avaliações impõe uma perspectiva. Ao sofrimento diante do imponderável, segue o seu testemunho, a sua afirmação, em suma, a aquiescência ilimitada ao 
que foi e ao que devém. No âmbito dessa aquiescência está, justamente, a percepção das interpretações como formas de o homem estar no mundo. Em Nietzsche, esse reconhecimento é indispensável, enquanto remete à aceitação das perspectivas impostas e ao reconhecimento do movimento de superação que requer a imposição de outras.

Entretanto, há uma supremacia da sua interpretação, manifesta no reconhecimento e na incorporação das demais interpretações, isto é, Nietzsche reconhece que houve outras interpretações que exprimiam uma visão de ser, de conhecer e de agir, incorporando-as no mundo enquanto seu círculo. O eterno retorno vem justamente expressar o decurso das interpretações, desde a instituição da idéia até a sua suspensão com a imposição da doutrina. Reconhecendo com sua instituição a desvalorização do mundo, expressa em termos teóricos e práticos, propõe, com o seu aniquilamento, a revalorização do mundo presente, tanto no seu perspectivismo quanto no amor fati. A inclusão da eternidade no mundo implica a rejeição de uma meta, de um alvo, de uma finalidade e, também, de punição, de condenação e de castigo. É a imanência da eternidade, por um lado, e o reconhecimento da ausência de responsabilidade, por outro, que cindem a compatibilidade entre culpa e ética. Se não há um criador, o decurso do mundo é inocente e, se não há deliberação, o processo da ação é justo. Logo, transparece o ponto decisivo do grande esforço de Zaratustra sobre si com relação à moral, qual seja, ser afirmativo a ponto de justificar mesmo o que passou: trata-se do reconhecimento da necessidade, do destino. Daí ele afirmar que em primeiro lugar está o necessário, sendo o reconhecimento dessa necessidade aquilo que se apresenta como o mais belo e perfeito que se poderá ter. Atingir essa dimensão de afirmação irrestrita da necessidade remete finalmente ao que seria a proposição de uma ética em Nietzsche como amor fati.

Quando Nietzsche aponta para a ausência de garantias em termos de felicidade, prazer, imortalidade e bem-aventurança, ele quer bem mais do que lançar o homem no sem sentido: trata-se de resgatar a sua potencialidade de criador de si e do mundo. Impondo perspectivas, ele se torna aquilo que ele é: um criador de valores. Eis o motivo que faz convergir crítica e construção no domínio dos valores. A crítica não nega a presença das demais interpretações no curso do tempo, nem mesmo a contraposição visa ao seu excluir. Ao contrário, a derradeira filosofia do autor de Assim falava Zaratustra conduz à afirmação dessas interpretações; mesmo o cristianismo vem a ser uma forma de o homem estar no mundo ao dotá-lo de valor. Se o filósofo alemão rejeita, em conjunto, as suas avaliações devido à transposição do valor ao plano imaginário, afirma sua presença no círculo mundano de interpretações: tanto o eterno retorno contempla a presença do sim ao conjunto de interpretações que 
negaram a efetividade, isto é, que introduziram a dualidade de mundos, e do sim especial de Nietzsche enquanto proponente de uma interpretação que visa a ampliar as perspectivas quanto o seu Übermensch manifesta a aquiescência às diversas interpretações, por reconhecer o seu vir-a-ser desde aquilo que ele é.

Os conceitos de Übermensch e amor fati estão estreitamente relacionados. Se o primeiro exprime a travessia trágica do criar e do destruir na ordem de uma aquiescência profunda, mesma aquiescência que liga Nietzsche, Zaratustra e Dionísio, o segundo elucida a tragicidade da travessia por resgatar os motivos não conscientes na base dos sentidos e valores que, ao conferirem gratuidade ao agir, remetem à mesma anuência. A intenção torna-se condição, o dever converte-se em imposição de perspectiva e o seu ser assim transmuda-se no movimento constante de seu vir-a-ser como fatum. O amor fati exprime a anuência à necessidade que vige em profundidade, ao reconhecer, na base das interpretações, um certo destino. A luta entre os impulsos introduz interpretações que revelam aproximadamente um plano desconhecido governado pelo pensar, querer e sentir que atravessa o corpo humano e impõem uma perspectiva de corpo social. Se não há causa primeira, também não existe razão última. Ao remeter a condição humana tãosomente às suas inclinações que manifestam necessidades, o amor fati conduz a afirmação do caráter fortuito da própria existência à sua singularidade, casualidade e finitude. É a aceitação da necessidade independentemente de justificativas que resgata a condição trágica do humano, na aquiescência àquilo que se é enquanto necessidade do que se vem a ser, no domínio das interpretações impostas. Enquanto interpretação ética, o amor fati expõe o processar-se da ação no homem como uma interpretação do próprio agir. Enfim, o percurso nietzschiano da dissolução da metafísica à ética do amor fati excluiu dos domínios interpretativos a noção de fundamento e conduziu à incompatibilidade entre culpa e ética. Eis o sentido do riso que atravessa Zaratustra.

Mas, Nietzsche também se inclui entre os "criadores" do mundo como filósofo. O conjunto da sua filosofia, particularmente a que se inicia em Assim falava Zaratustra, é uma leitura do mundo, em seu conjunto, que se reconhece como perspectiva. O percurso dos existentes, enquanto multiplicidades de vontades de potência, ao amor fati deve-se ao reconhecimento de que não há outro modo de estar no mundo exceto o interpretante. Por isso, a aquiescência profunda endereça-se ao conjunto de interpretações postas no tempo, mesmo ao cristianismo, pois constituem formas de o homem situar-se no mundo desde a atribuição de determinados predicados provisórios. Remete igualmente à assimilação das condições dos existentes que introduziram essas interpretações. 
Querer o necessário é querer, ao mesmo tempo, as condições e as interpretações, pois Nietzsche não distingue signo, significante e significado. Logo, as condições são as interpretações sempre, estritamente, perspectivas. Estar no mundo, desde essa compreensão de que só há sentido e valor, quer dizer, rejeitar a existência de fatos e fundamentos enquanto predicados do mundo e da vida, requer o reconhecimento da finitude humana enquanto sua irrecusável condição, que faz do introduzir interpretações e do suportar o seu caráter finito a grandeza no homem. A criação nietzschiana consistiu em dissolver a metafísica e prescrever a aceitação incondicional das formas através das quais o homem se situou no mundo, ou seja, por meio da afirmação irrestrita das suas interpretações, mediante a introdução de uma interpretação mais abrangente, que reconhece, na vontade de potência, no além-do-homem e no eterno retorno a introdução de uma perspectiva que conduz à aceitação incondicional da vida. Com a doutrina do eterno retorno, ele estanca o processo de progressão da idéia que prescrevia a "mendacidade ante o necessário", para remeter ao "nada querer diferente, seja para trás, seja para a frente, seja em toda a eternidade". Através do amor fati, Nietzsche resgata o dizer sim à vida mesma e conduz o homem ao eterno prazer do vir-a-ser, mediante a simplicidade do criar e do destruir que o faz:

"Zaratustra desceu a montanha sozinho e sem encontrar ninguém. Mas, quando chegou às florestas, deparou repentinamente com um velho, que deixara a sua sagrada choupana para ir à procura de raízes no mato. E assim falou o velho a Zaratustra:

'Não me é desconhecido esse viandante; passou por aqui há muitos anos. Chamava-se Zaratustra; mas está mudado. (...)

Sim, reconheço Zaratustra. Puro é seu olhar e não há em sua boca nenhum laivo de náusea. Não será por isso que caminha como um dançarino?

Mudado está Zaratustra, tornou-se uma criança, Zaratustra despertou...'” (ZA "O prólogo de Zaratustra"). 